\title{
Peningkatan Hasil Belajar dengan Penerapan Model Pembelajaran Guided Discovery Learning pada Materi Persamaan Linier Satu Variabel
}

\author{
Muhamad Saleh $^{\left.1^{*}\right)}$, Helvi Satifa' ${ }^{2)}$ \& Nur Ainun ${ }^{3)}$ \\ 1, 2, ${ }^{3}$ Universitas Serambi Mekkah, Banda Aceh, Indonesia
}

\section{INFO ARTICLES}

Article History:

Received: 31-03-2021

Revised: 23-06-2021

Approved: 25-06-2021

Publish Online: 30-06-2021

\section{KeyWords:}

Guided Discovery; Learning; Linear Equation One Variable;

\section{(1) (2)}

\begin{abstract}
Efforts to overcome students' difficulties in One Variable Linear Equation (PLSV) are to develop appropriate learning models so that students understand the material well. One of the learning models that can improve student learning outcomes in solving PLSV questions is the Guided Discovery Learning model. The purpose of this study was to determine the improvement of PLSV learning outcomes through Guided Discovery Learning. This study uses the type of pre-experimental research. The population in this study were students of class VIII. The sample was taken from one class, namely class VIII ${ }^{1}$ with 29 students. Data collection in this study was carried out using various kinds of material descriptions of linear equations one variable 5 questions with a maximum score of 100. Then the t test (right side test) was used with $\alpha=0.05$; to test the hypothesis. Based on the results of Key's research that Guided Discovery Learning material Linear Equation One Variable in class VIII junior high school students has been improved with the medium category.
\end{abstract}

\begin{abstract}
Abstrak: Upaya mengatasi kesulitan siswa dalam Persamaan Linier Satu Variabel (PLSV) dengan menyusun model pembelajaran yang tepat agar siswa memahami materi dengan baik. Salah satu model pembelajaran yang dapat meningkatkan hasil belajar siswa dalam menyelesaikan soal PLSV adalah model Guided Discovery Learning. Tujuan penelitian ini untuk mengetahui Peningkatan Hasil Belajar PLSV melalui pembelajaran Guided Discovery Learning. Penelitian ini mengunakan jenis penelitian pre eksperimen. Populasi dalam penelitian ini siswa kelas VIII. Sampel diambil satu kelas yaitu kelas VIII ${ }^{1}$ berjumlah 29 orang siswa. Pengumpulan data dalam penelitian ini dilakukan dengan menggunakan tes butir berbentuk uraian pada materi persamaan linier satu variabel sebanyak 5 soal dengan skor maksimal 100. Kemudian digunakan uji-t (uji pihak kanan) dengan $\alpha=0,05$; untuk menguji Hipotesis. Berdasarkan hasil penelitian disimpulkan bahwa Pembelajaran Guided Discovery Learning materi Persamaan Linier Satu variabel pada siswa SMP kelas VIII telah diperoleh peningkatan dengan katagori sedang.
\end{abstract}

Correspondence Address: Jln. Kechik Amik 1 Lrg Mawar Nomor 4 Komp BHI-3 Mns Krueng Kecamatan Ingin Jaya Aceh Besar, Indonesia; e-mail: msalehginting@gmail.com

How to Cite (APA $6^{\text {th }}$ Style): Saleh, M., Satifa, H., \& Ainun, N. (2021). Peningkatan Hasil Belajar dengan Penerapan Model Pembelajaran Guided Discovery Learning pada Materi Persamaan Linier Satu Variabel. JKPM (Jurnal Kajian Pendidikan Matematika), 6(2): 255-266.

Copyright: 2021 Muhamad Saleh, Helvi Satifa, Nur Ainun

Competing Interests Disclosures: The authors declare that they have no significant competing financial, professional or personal interests that might have influenced the performance or presentation of the work described in this manuscript. 


\section{PENDAHULUAN}

Pelajaran matematika merupakan mata pelajaran dasar yang harus dikuasai oleh siswa, karena matematika merupakan penunjang ilmu pengetahuan lainnya (Saleh et. al. 2019, Saleh and Mahmuzah 2019). Matematika merupakan salah satu ilmu pengetahuan yang selalu diajarkan kepada semua siswa mulai dari tingkat sekolah dasar sampai perguruan tinggi, untuk membekali siswa agar memiliki kemampuan berfikir logis, analitis, sistematis, kritis, dan kreatif. Siswa seringkali mengalami kesulitan untuk memahami matematika karena matematika memiliki sifat salah satunya adalah abstrak karena itu membutuhkan penalaran yang cukup tinggi dalam memahami (Ferawati, \& Suhendri, 2020).

Berpikir kreatif membutuhkan aktivitas mental seperti, mengajukan pertanyaan, mempertimbangkan informasi daru dan ide yang tidak lazim dengan pikiran terbuka, membangun keterkaitan diantara hal yang berbeda, menghubungkan berbagai hal dengan bebas, menerapkan imajinasi pada setiap situasi untuk menghasilkan hal baru, serta mendengarkan intuisi (Indiastuti, 2017). Berdasarkan hasil pertemuan dengan pihak guru yang mengajar di sekolah tempat penelitian diperoleh keterangan bahwa, salah satu kesulitan yang dihadapi siswa adalah Persamaan Linier Satu Variabel (PLSV). Mereka beranggapan bahwa materi PLSV itu sulit untuk dimengerti, sehingga menyulitkan siswa dalam mengingat dan memilah-milah antara pokok bahasan satu dengan pokok bahasan yang lain. Di sisi lain bahwa masalah-masalah yang diajukan pada SPLSV selalu berkaitan dengan masalah yang dihadapi dalam kehidupan sehari. Adanya penggunaan variabel pada PLSV manjadi bagian dari kesulitan siswa. Penyebab lain tentunya kurangnya motivasi dan aktivitas siswa dalam mengikuti proses pembelajaran disebabkan oleh siswa itu sendiri. Oleh karena itu, upaya untuk mengatasi kesulitan siswa dalam PLSV dengan menyusun strategi model pembelajaran yang tepat agar siswa dapat memahami materi dengan lebih baik dan mendalam. Guru perlu menerapkan suatu metode pembelajaran yang membuat siswa berkesempatan untuk berinteraksi satu sama lainnya yang memungkinkan mereka mencintai proses belajar mengajar (Marantika, \& Handayani, 2015). Agar siswa dapat mencapai tujuan pembelajaran yang diharapkan diperlukanlah sebuah model pembelajaran yang inovatif yang mampu mengubah anggapan negatif tentang matematika, mengubah pola pikir siswa terhadap matematika dan menciptakan suasana belajar matematika lebih mudah dan menyenangkan agar siswa termotivasi untuk mempelajari matematika. Salah satu model pembelajaran yang dapat digunakan yaitu model pembelajaran kooperatif Nurhayati, \& Marliani, (2019). Dalam hal ini salah satu model pembelajaran yang dapat meningkatkan hasil belajar siswa dalam menyelesaikan soal PLSV adalah model Guided Discovery Learning.

Model pembelajaran Guided Discovery Learning adalah suatu pendekatan mengajar di mana guru memberi siswa contoh-contoh topik spesifik dan memandu siswa untuk memahami topik tersebut. Keuntungan dari model pembelajaran Guided Discovery Learning yaitu (a) pengetahuan ini dapat bertahan lama, mudah diingat dan mudah diterapkan pada situasi baru, (b) meningkatkan penalaran, analisis dan keterampilan siswa memecahkan masalah tanpa pertolongan orang lain, (c) menigkatkan kreatifitas siswa untuk terus belajar dan tidak hanya menerima saja, (d) terampil dalam menentukan konsep atau memecahkan masalah. For learning the mathematical concepts need to have special skills (Amir-Mofidi, Amiripour, \& Bijan-Zadeh 2012).

"Model Guided Discovery Learning (temuan terbimbing) adalah satu pendekatan mengajar dimana guru memberi siswa contoh-contoh topik spesifik dan memandu siswa untuk memahami topik tersebut" (Eggen, 2012). Menurut Widodo (2010) bahwa belajar penemuan sesuai dengan pencarian pengetahuan secara aktif oleh manusia, dan dengan sendirinya memberikan hasil yang paling baik. Berusaha sendiri untuk mencari pemecahan masalah serta pengetahuan yang menyertainya, menghasilkan pengetahuan yang benar-benar bermakna. The experienced thingswill leave stronger trace compared to the one gained from reading or listening (Saleh et. al. 2018). 
Model pembelajaran Guided Discovery Learning diharapkan dapat meningkatkan peran aktif siswa dalam pembelajaran sehingga siswa dapat mencapai kriteria ketuntasan Minimal (KKM) seperti yang telah ditetapkan.Model Pembelajaran Guided Discovery Learningjuga dapat Meningkatkan Hasil Belajar, dengan adanya model Guided Discovery Learning dapat membuat pemikiran siswa lebih aktif dan tanggap dalam menjawab soal PLSV.

\section{METODE}

Pendekatan yang digunakan dalam penelitian ini adalah pendekatan kuantitatif, yaitu suatu proses menemukan pengetahuan yang menggunakan data berupa angka sebagai alat menentukan keterangan mengenai apa yang ingin kita ketahui. Penelitian kuantitatif pada umunya dilakukan pada sampel yang dari populasi secara random dan kesimpulan hasil penelitian digeneralisasikan pada populasi dimana sampel tersebut diambil (Sugiyono, 2014:8). Pada penelitian ini, peneliti menggunakan penelitian eksperimen yaitu jenis pre-eksperimen, dengan desain one shoot case study, yang digambarkan seperti diagram (Gambar 1.)

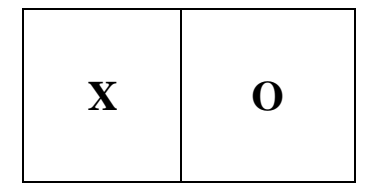

Keterangan:

\section{Gambar 1. Diagram Desain One Shoot Case Study}

$\mathrm{X}$ adalah treatment atau perlakuan

$\mathrm{O}$ adalah hasil observasi sesudah treatment

Pada penelitian ini yang menjadi subjek penelitian adalah satu kelas dengan satu kali tes setelah pembelajaran, sehingga digolongkan dalam desain one-shot case study. Hal ini sesuai dengan (Arikunto 2005), yang menyatakan bahwa rancangan studi kasus satu tembakan adalah sebuah eksperimen yang dilaksanakan tanpa adanya kelompok pembanding dan juga tanpa tes awal. Penelitian ini dilaksanakan pada salah satu SMPN Banda Aceh kelas VIII, dilakukan pada semester ganjil tahun pelajaran 2017/2018.

Populasi adalah wilayah generalisasi yang terdiri dari: obyek/subyek yang mempunyai kualitas dan karakteristik tertentu yang ditetapkan oleh peneliti untuk dipelajari dan kemudian ditarik kesimpulannya, sedangkan sampel adalah bagian dari jumlah dan karakteristik yang dimiliki oleh populasi tersebut (Sugiyono, 2014:80). Sebagai populasi dalam penelitian ini adalah siswa-siswi kelas VIII SMP. Berdasarkan jumlah populasi yang ada, selanjutnya penulis hanya mengambil satu kelas dari seluruh kelas VIII pada salah satu SMP Negeri di Banda Aceh. Pengambilan sampel dilakukan secara purposive sampling, yaitu teknik sampling yang digunakan oleh peneliti jika peneliti mempunyai pertimbangan-pertimbangan tertentu di dalam pengambilan sampelnya (Sugiyono 2014).

Teknik pengumpulan data berupa tes, tes yang dilakukan sebanyak dua kali yaitu tes awal(PreTest) dan tes akhir (Post-Test). Tes Pre-Test menggunakan instrumen yang disusun oleh guru bidang study matematika tanpa menggunakan pembelajaran Guide Discovery Learning, sedangkan Post-Test menggunakan instrumen yang disusun oleh peneliti setelah menggunakan pembelajaran Guide Discovery Learning. Tes yang digunakan untuk menguji taraf penguasaan siswa atas materi yang telah diajarkan. Hasil tes yang didapatakan digunakan untuk mengetahui peningkatan hasil belajar PLSV melalui pembelajaran Guided Discovery Learning.Post-test yang disusun berpedoman pada Kurikulum 2013. Tes hasil belajar berbentuk soal uraian sebanyak 5 soal, dengan skor ideal/keseluruhannya adalah 100 .

Peneliti mengolah dan menganalisis data yang telah diperoleh dengan menggunakan statistik uji-t sebagai uji hipotesis. Data dari tes yang diperoleh dalam penelitian ini, diuji dengan statistik uji- 
$\mathrm{t}$ pada tarf signifikan $\alpha=0,05$. Sebelum menggunakan statistik uji-t terlebih dahulu diuji untuk melihat persyaratan analisisnya yaitu normalitas sebaran data.

Uji normalitas sebaran data dilakukan terlebih dahulu karena sebagai persyaratan uji-t, data harus berdistribusi normal. Pengujian normalitas data diperlukan untuk mengetahui apakah data yang telah diperoleh dari data tes siswa berdistribusi normal atau tidak. Untuk menguji normalitas data, digunakan statistik chi-kuadrat seperti yang dikemukakan (Sugiyono 2013) sebagai berikut:

$$
\chi^{2}=\sum_{i=1}^{k} \frac{(O i-E i)^{2}}{E i}
$$

$O_{i} \quad=$ frekuensi pengamatan

$E_{i} \quad=$ frekuensi yang diharapkan

Pengujian hipotesis dalam penelitian ini menggunakan uji-t pihak kanan dengan taraf signifikan $(\alpha)=0,05$. Untuk menguji hipotesis yang telah dirumuskan, menurut (Sugiyono 2013) dapat digunakan statistik uji-t sebagai berikut:

Keterangan:

$$
t=\frac{\bar{x}-\mu_{0}}{\frac{s}{\sqrt{n}}}
$$

$$
\begin{aligned}
& \bar{x}=\text { Nilai rata }- \text { rata } \\
& \mu o=\text { Nilai ketuntasan } \\
& \mathrm{s}=\text { Simpangan baku } \\
& \mathrm{n}=\text { Banyak Data }
\end{aligned}
$$

The Hake test allows for a comparison of gains between samples that have taken pretests and posttests on the same instrument (Culbertson, et. al. 2008). Skor gain aktual yaitu skor gain yang diperoleh siswa sedangkan skor gain maksimal yaitu skor gain tertinggi yang mungkin diperoleh siswa. The formula for computing the Hake gain for an individual student is:

$$
\mathrm{N}-\mathrm{Gain}(\mathrm{g})=\frac{\text { posttest score }- \text { pretest score }}{\text { total possible }- \text { pretest score }} \quad \text { (Culbertson, et. al. 2008) }
$$

Dalam menganalisis data skor gain ternormalisasi, tahapannya sama dengan menganalisis data skor pre-test, a) Uji normalitas; b) Uji homogenitas; c) Uji perbedaan rata-rata (dua pihak).

Hasil perhitungan N_gain kemudian diinterprestasikan dengan menggunakan klasifikasi berdasarkan kategori High-g, Medium-g, dan Low-g, lebih jelasnya disajikan dalam tabel

Tabel 1. Klasifikasi dari Hasil Perhitungan N_gain

\begin{tabular}{cc}
\hline Besarnya N-Gain & Klasifikasi \\
\hline $\mathrm{g}>0,7$ & High-g \\
$0,3<\mathrm{g} \leq 0,7$ & Medium-g \\
$\mathrm{g} \leq 0,3$ & Low- $\mathrm{g}$ \\
\hline
\end{tabular}

Sumber: (Hake, 2009)

\section{HASIL}

Data dalam penelitian ini dikumpulkan dari tes awal (pre-test) dan tes akhir (post-test) yang diberikan kepada siswa kelas VIII ${ }^{1}$ pada pokok bahasan PLSV melalui pembelajaran Guided Discovery Learning yang berjumlah 29 siswa yang berbentuk soal essay sebanyak 5 soal. Setelah tes diberikan, peneliti memeriksa lembar jawaban siswa dan memberi skor terhadap hasil jawaban tersebut. Skor yang diberikan untuk setiap nomor berbeda sesuai tingkat kesulitan soal.

Pembelajaran dengan menggunakan Pembelajaran Guided Discovery Learning ini dapat mencapai ketuntasan hasil belajar siswa kelas VIII ${ }^{1}$ pada materi Persamaan Linier Satu variabel, diperoleh dari pemberian tes yang dilakukan sebanyak dua kali yaitu tes awal (Pre-Test) dan tes akhir 
(Post-Test). Hasil tes awal menunjukkan bahwa tidak ada siswa yang mencapa inilai ketuntasan, sedangkan pada hasil tesakhir siswa sudah mencapai ketuntasan. Akan tetapi ada 6 siswa yang tidak mencapai ketuntasan hasil belajar dalam menyelesaikan soal PLSV yang diberikan. Nilai yang diperoleh siswa sangat bervariasi, mulai dari nilai tertinggi, sedang, dan terendah.

Tabel 2. Data Pre-Tes PLSV) Melalui Pembelajaran Guided discovery Learning

\begin{tabular}{|c|c|c|c|c|c|c|c|c|c|c|}
\hline \multirow{2}{*}{ No. } & \multirow{2}{*}{$\begin{array}{l}\text { Kode } \\
\text { Siswa }\end{array}$} & \multicolumn{4}{|c|}{ No. Soal dan Skor } & & Jumlah & \multirow{2}{*}{$\begin{array}{c}\text { Persentase } \\
(\%)\end{array}$} & \multicolumn{2}{|c|}{ Tuntas } \\
\hline & & 1 & 2 & 3 & 4 & 5 & Skor & & $\mathrm{Ya}$ & Tidak \\
\hline 1 & AA & 10 & 10 & 5 & 5 & 5 & 35 & 35 & - & $\sqrt{ }$ \\
\hline 2 & $\mathrm{AL}$ & 5 & 5 & 25 & 10 & 20 & 67 & 67 & - & $\sqrt{ }$ \\
\hline 3 & $\mathrm{ARH}$ & 5 & 8 & 25 & 10 & 20 & 68 & 68 & - & $\sqrt{ }$ \\
\hline 4 & AR & 5 & - & 5 & 20 & 20 & 50 & 50 & - & $\sqrt{ }$ \\
\hline 5 & BA & 5 & 10 & 20 & 15 & 20 & 70 & 70 & - & $\sqrt{ }$ \\
\hline 6 & DF & 5 & 5 & 25 & 10 & 20 & 65 & 65 & - & $\sqrt{ }$ \\
\hline 7 & DAR & 5 & 12 & 25 & - & - & 42 & 42 & - & $\sqrt{ }$ \\
\hline 8 & $\mathrm{DM}$ & 5 & 5 & 25 & 10 & 20 & 65 & 65 & - & $\sqrt{ }$ \\
\hline 9 & $\mathrm{H}$ & 5 & 10 & 20 & 5 & - & 40 & 40 & - & $\sqrt{ }$ \\
\hline 10 & IP & 10 & 10 & 5 & 5 & 5 & 35 & 35 & - & $\sqrt{ }$ \\
\hline 11 & I & 10 & 5 & 5 & 15 & - & 35 & 35 & - & $\sqrt{ }$ \\
\hline 12 & KA & 5 & 5 & 25 & 10 & 20 & 65 & 65 & - & $\sqrt{ }$ \\
\hline 13 & LI & 5 & 10 & 20 & 15 & 20 & 70 & 70 & - & $\sqrt{ }$ \\
\hline 14 & MDP & 5 & 7 & 22 & 10 & 20 & 64 & 64 & - & $\sqrt{ }$ \\
\hline 15 & MWA & 5 & 5 & 12 & 10 & 10 & 42 & 42 & - & $\sqrt{ }$ \\
\hline 16 & $\mathrm{MF}$ & 5 & 7 & 15 & 10 & - & 37 & 37 & - & $\sqrt{ }$ \\
\hline 17 & NR & 5 & 13 & 10 & 8 & 10 & 46 & 46 & - & $\sqrt{ }$ \\
\hline 18 & PSL & 5 & 5 & 25 & 5 & 20 & 60 & 60 & - & $\sqrt{ }$ \\
\hline 19 & QN & 5 & 10 & 25 & 10 & 20 & 70 & 70 & - & $\sqrt{ }$ \\
\hline 20 & RSW & 5 & 12 & 5 & 8 & 5 & 35 & 35 & - & $\sqrt{ }$ \\
\hline 21 & $\mathrm{RR}$ & 5 & 13 & 10 & 8 & 10 & 46 & 46 & - & $\sqrt{ }$ \\
\hline 22 & $\mathrm{RB}$ & 5 & 3 & 25 & 20 & 10 & 63 & 63 & - & $\sqrt{ }$ \\
\hline 23 & $\mathrm{~S}$ & 10 & 12 & 10 & 10 & 10 & 52 & 52 & - & $\sqrt{ }$ \\
\hline 24 & SA & 5 & 3 & 25 & 8 & 20 & 61 & 61 & - & $\sqrt{ }$ \\
\hline 25 & SR & 10 & 10 & 10 & 10 & 10 & 50 & 50 & - & $\sqrt{ }$ \\
\hline 26 & WK & 5 & 13 & 10 & 8 & 10 & 46 & 46 & - & $\sqrt{ }$ \\
\hline 27 & $\mathrm{DS}$ & 10 & 10 & 10 & 10 & 10 & 50 & 50 & - & $\sqrt{ }$ \\
\hline 28 & $\mathrm{AG}$ & 5 & 12 & 25 & - & - & 42 & 42 & - & $\sqrt{ }$ \\
\hline 29 & $\mathrm{R}$ & 10 & 10 & 20 & 8 & 10 & 58 & 58 & - & $\sqrt{ }$ \\
\hline & amlah & 180 & 240 & 489 & 273 & 355 & 1536 & & $\begin{array}{c}0 \\
(0 \%)\end{array}$ & $\begin{array}{c}29 \\
(100 \%)\end{array}$ \\
\hline
\end{tabular}

Sumber: diolah dari data penelitian 
Tabel 3. Data Pots-Tes Siswa PLSV Melalui Pembelajaran Guided discovery Learning

\begin{tabular}{|c|c|c|c|c|c|c|c|c|c|c|}
\hline \multirow{2}{*}{ No } & \multirow{2}{*}{$\begin{array}{l}\text { Kode } \\
\text { Siswa }\end{array}$} & \multicolumn{4}{|c|}{ No. Soal dan Skor } & \multirow[b]{2}{*}{5} & \multirow{2}{*}{$\begin{array}{c}\text { Jumlah } \\
\text { Skor }\end{array}$} & \multirow{2}{*}{$\begin{array}{c}\text { Persentase } \\
(\%)\end{array}$} & \multicolumn{2}{|c|}{ Tuntas } \\
\hline & & 1 & 2 & 3 & 4 & & & & $\mathrm{Ya}$ & Tidak \\
\hline 1 & AA & 10 & 10 & 20 & 20 & 5 & 65 & 65 & - & $\sqrt{ }$ \\
\hline 2 & $\mathrm{AL}$ & 10 & 15 & 25 & 20 & 10 & 80 & 80 & $\sqrt{ }$ & - \\
\hline 3 & $\mathrm{ARH}$ & 10 & 15 & 25 & 20 & 10 & 80 & 80 & $\sqrt{ }$ & - \\
\hline 4 & $\mathrm{AR}$ & 10 & 10 & 28 & 20 & 10 & 78 & 78 & $\sqrt{ }$ & - \\
\hline 5 & BA & 10 & 15 & 25 & 20 & 25 & 95 & 95 & $\sqrt{ }$ & - \\
\hline 6 & DF & 10 & 15 & 12 & 20 & 25 & 82 & 82 & $\sqrt{-}$ & - \\
\hline 7 & DAR & 10 & 15 & 10 & 20 & 20 & 75 & 75 & $\sqrt{ }$ & - \\
\hline 8 & $\mathrm{DM}$ & 10 & 15 & 25 & 20 & 15 & 85 & 85 & $\sqrt{ }$ & - \\
\hline 9 & $\mathrm{H}$ & 10 & 10 & 20 & 20 & 20 & 80 & 80 & $\sqrt{ }$ & - \\
\hline 10 & IP & 6 & 10 & 20 & 20 & 10 & 66 & 66 & - & $\sqrt{ }$ \\
\hline 11 & I & 10 & 10 & 15 & 15 & 20 & 70 & 70 & - & $\sqrt{ }$ \\
\hline 12 & KA & 10 & 15 & 30 & 18 & 10 & 83 & 83 & $\sqrt{ }$ & - \\
\hline 13 & $\mathrm{LI}$ & 10 & 15 & 25 & 20 & 25 & 95 & 95 & $\sqrt{ }$ & - \\
\hline 14 & MDP & 10 & 10 & 28 & 20 & 20 & 88 & 88 & $\sqrt{ }$ & - \\
\hline 15 & MWA & 10 & 15 & 25 & 20 & 15 & 85 & 85 & $\sqrt{ }$ & - \\
\hline 16 & $\mathrm{MF}$ & 10 & 15 & 25 & 15 & 10 & 75 & 75 & $\sqrt{ }$ & - \\
\hline 17 & NR & 10 & 10 & 28 & 20 & 20 & 88 & 88 & $\sqrt{ }$ & - \\
\hline 18 & PSL & 10 & 15 & 15 & 17 & 20 & 77 & 77 & $\sqrt{ }$ & - \\
\hline 19 & QN & 10 & 15 & 25 & 17 & 20 & 87 & 87 & $\sqrt{ }$ & - \\
\hline 20 & RSW & 10 & 15 & 10 & 20 & 20 & 75 & 75 & $\sqrt{ }$ & - \\
\hline 21 & $\mathrm{RR}$ & 10 & 15 & 25 & 15 & 20 & 85 & 85 & $\sqrt{ }$ & - \\
\hline 22 & $\mathrm{RB}$ & 10 & 10 & 30 & 20 & 10 & 80 & 80 & $\sqrt{ }$ & - \\
\hline 23 & S & 10 & 15 & 17 & 20 & 25 & 87 & 87 & $\sqrt{ }$ & - \\
\hline 24 & SA & 10 & 10 & 20 & 20 & 20 & 80 & 80 & $\sqrt{ }$ & - \\
\hline 25 & SR & 10 & 10 & 20 & 15 & 15 & 70 & 70 & - & $\sqrt{ }$ \\
\hline 26 & WK & 10 & 15 & 15 & 10 & 10 & 60 & 60 & - & $\sqrt{ }$ \\
\hline 27 & DS & 10 & 15 & 25 & 20 & 5 & 75 & 75 & $\sqrt{ }$ & - \\
\hline 28 & AG & 10 & 15 & 20 & 20 & 10 & 75 & 75 & $\sqrt{ }$ & \\
\hline 29 & $\mathrm{R}$ & 10 & 10 & 20 & 10 & 10 & 60 & 60 & - & $\sqrt{ }$ \\
\hline & Imlah & & & & & & & & $\begin{array}{c}23 \\
(79 \%)\end{array}$ & $\begin{array}{c}6 \\
(21 \%) \\
\end{array}$ \\
\hline
\end{tabular}

Sumber: diolah dari data penelitian

Penelitian ini dilakukan di sekolah yang tidak ada pengelompokan kelas (pembedaan kelas antara siswa pintar dengan siswa kurang pintar). Pada proses pembelajaran dalam kelas yang terdiri dari berbagai kemampuan sering terjadi hanya siswa yang memiliki kemampuan yang lebih cepat yang dapat langsung mengikuti proses pembelajaran, sedangkan siswa yang lain masih lebih banyak diam saat pembelajaran dengan Pembelajaran Guided Discovery. Kondisi seperti ini terjadi pada pertemuan pertama dan belum bisa dikondisikan secara optimal.

Berdasarkan hasil tes siswa, terdapat peningkatan/selisih skor perolehan siswa antara pre-test dan postes. Peningkatan skor terjadi untuk setiap siswa dengan katagori sedang. Peningkatan skor tertinggi dan terendah secara berturut-turut adalah 42 dan 2, sedangkan rata-rata skor peningkatan adalah 25,76 . Sedangkan besarnya gain score yang diperoleh adalah 10,932 dengan rata-rata adalah 0,38 berada pada katagori sedang. 
Pada diskusi kelompok yang pertama, siswa masih bingung dalam mengerjakan Lembar Kerja Siswa (LKS) yang diberikan karena mereka belum terbiasa mencari sendiri informasi yang diberikan dalam soal. Siswa yang pintar pun lebih senang mengerjakan sendiri dan kurang mau bekerja sama dengan anggota lainnya. Pada saat perwakilan kelompok diminta untuk mempresentasikan hasil diskusinya didepan kelas, siswa terlihat masih malu-malu dan masih sulit untuk menyampaikan kepada siswa lainnya mengenai hasil diskusi kelompoknya, sehingga siswa lain lebih banyak mengobrol dan enggan menanggapi presentasi temannya. Hal ini disebabkan kebiasaan siswa pada pembelajaran sebelumnya yang berpusat pada guru, siswa hanya mendengarkan dan mencatat apa ditulis guru di depan kelas, mengerjakan soal yang mirip dengan contoh dan kurang adanya interaksi antara siswa sehingga mereka belum terbiasa untuk menyampaikan pendapat ataupun bertanya jika ada penjelasan yang belum dipahami.

Pada pertemuan selanjutnya (seluruhnya 6 pertemuan), sedikit demi sedikit ada perubahan yang baik pada siswa, hal inidilihat dari hasil diskusi siswa dan hasil latihan. Siswa dapat memecahkan masalah dalam menjawab pertanyaan soal dan bertanya jika mereka mengalami kesulitan dalam menyelesaikan masalah ataupun kurang memahami materi. Siswa punlebih berani mempresentasikan hasil diskusi kelompoknya didepan kelas dan siswa yang lain pun tidak ragu-ragu dalam mengungkapkan pendapatnya. Dalam penelitian ini ditemukan beberapa kendala di dalam implementasi penggunaan Pembelajaran Guided Discovery, diantaranya siswa tidak dapat memecahkan masalah soal, sehingga soal-soal tidak terselesaikan karena kurang pemahaman pemecahan masalah. Upaya yang dilakukan adalah menambah pemahaman dalam pemecahan masalah dalam soal pada pelajaran matematika. Siswa hanya memperoleh informasi berdasarkan penjelasan guru. Guru lebih berperan sebagai instruktur yang melakukan proses pembelajaran dari pada fasilitator. Siswa cenderung pasif dan tidak memperoleh pemahaman soal cerita melalui pengalamannya sendiri. Siswa hanya menyelesaikan suatu permasalahan dengan pengetahuan yang disampaikan oleh gurunya saja, sehingga dapat menghambat respon siswa.

\section{PEMBAHASAN}

Setelah melakukan evaluasi, diperoleh hasil tes siswa tentang materi Persamaan Linier Satu variabel dan uraian tentang jenis kesulitan siswa berdasarkan dari jawaban yang mereka berikan. Dimana jenis kesulitan tersebut yaitu mereka kurang memahami dan kurang mengerti dalam soal pada materi PLSV. Salah satu kesalahan siswa dalam menjawab soal dapat dilihat pada Tabel 4. Berdasarkan dalam Tabel 4., tampak bahwa jawabannya salah. Siswa tidak menguasai konsep dari PLSV. Pada jawaban siswa untuk soal no. 5, masih ada kesilapan dalam menyelesaikan soal, siswa hanya mencari panjang tanah saja, tidak menyelesaikan sampai akhir.

Sedangkan soal yang diberikan sebagai berikut:

\section{Soal no. 5}

"Pak Amin memiliki sebidang tanah berbentuk persegi panjang dengan lebar $5 \mathrm{~m}$ lebih pendek dari panjangnya. Keliling tanah pak Amin adalah $50 \mathrm{~m}$. Berapakah ukuran panjang dan lebar tanah pak Amin?" 


\section{Tabel 4. Jawaban Siswa (Pre-Test) yang Salah dan Belum Mencapai Nilai KKM}

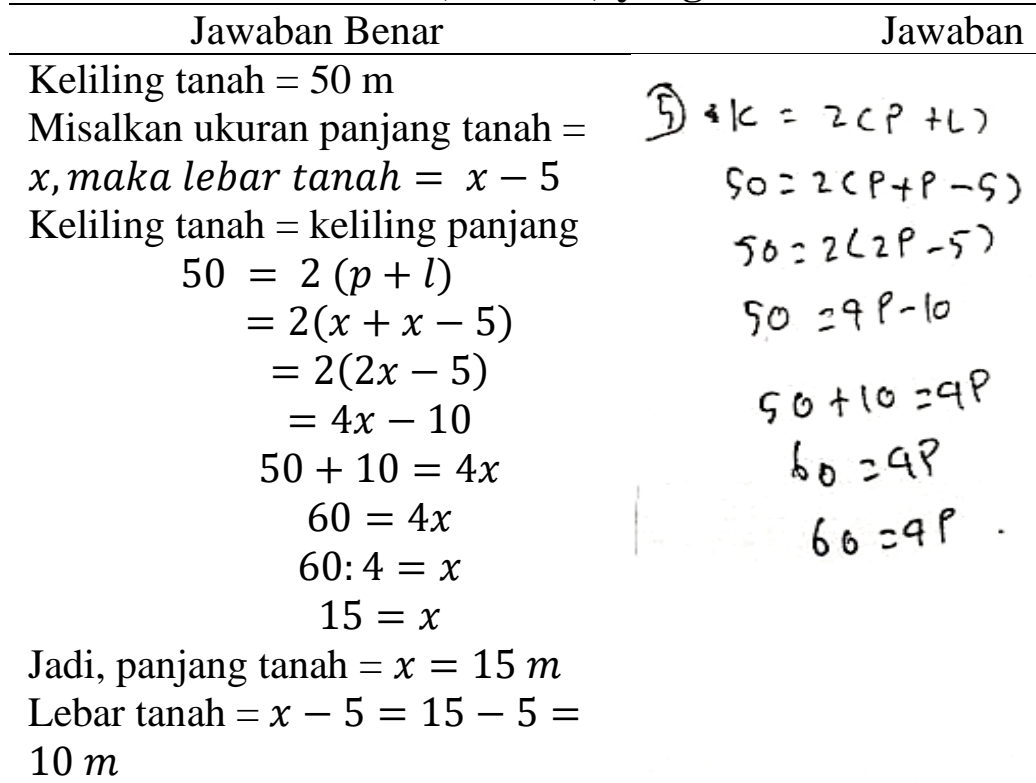

Sumber: diolah dari data penelitian

Adapun beberapa siswa yang sudah paham dalam menyelesaikan soal-soal operasi aljabar dengan benar. Berikut akan diuraikan jawaban siswa dalam menyelesaikan soal operasi aljabar yang disajikan dalam Tabel 5. Berdasarkan Tabel 5., siswa ini sudah memahami soal dan sudah mampu menyelesaikan dengan benar. Dengan menyelesaikan penyelesaiannya dengan memisalkan banyak permen yang diminta oleh adiknya Udin sebanyak $x$ permen dan mengurangkan kedua ruas.

Berdasarkan kenaikan nilai rata-rata yang diperoleh siswa pada Tabel 2. dan Tabel 3., penulis menyimpulkan bahwa penerapan pembelajaran Guided Discovery terdapat peningkatan terhadap hasil belajar siswa pada materi PLSV, karena dalam pembelajaran ini siswa lebih aktif yaitu berani bertanya dan berbagi informasi dengan guru dan teman, dapat memecahkan masalah dengan cara mereka masing-masing, berani mengungkapkan pendapat mereka, berani tampil yaitu siswa berani memaparkan hasil kerja mereka di depan kelas, memiliki kebebasan dalam memecahkan masalah dan dapat menyenangi aktivitas matematika menurut kemampuan siswa masing-masing. Pembelajaran matematika yang awalnya dirasa sulit, membosankan, dan terlalu monoton dalam belajar akan menjadi menyenangkan.

Dalam hal ini, soal yang diberikan kepada siswa sebagai berikut:

\section{Soal no.2}

"Udin membeli 20 permen di warung yang ada di dekat rumahnya. Ketika sudah di rumah, adik-adiknya (Abdul, Masitah, dan Nasar) meminta permen tersebut sehingga permen Budi tersisa 11 biji. Maka permen Udin $(20-x=11)$. Berapa banyak permen yang diminta oleh ketiga adiknya Udin?" 
Tabel 5. Hasil Jawaban Siswa yang Telah Mencapai Nilai KKM

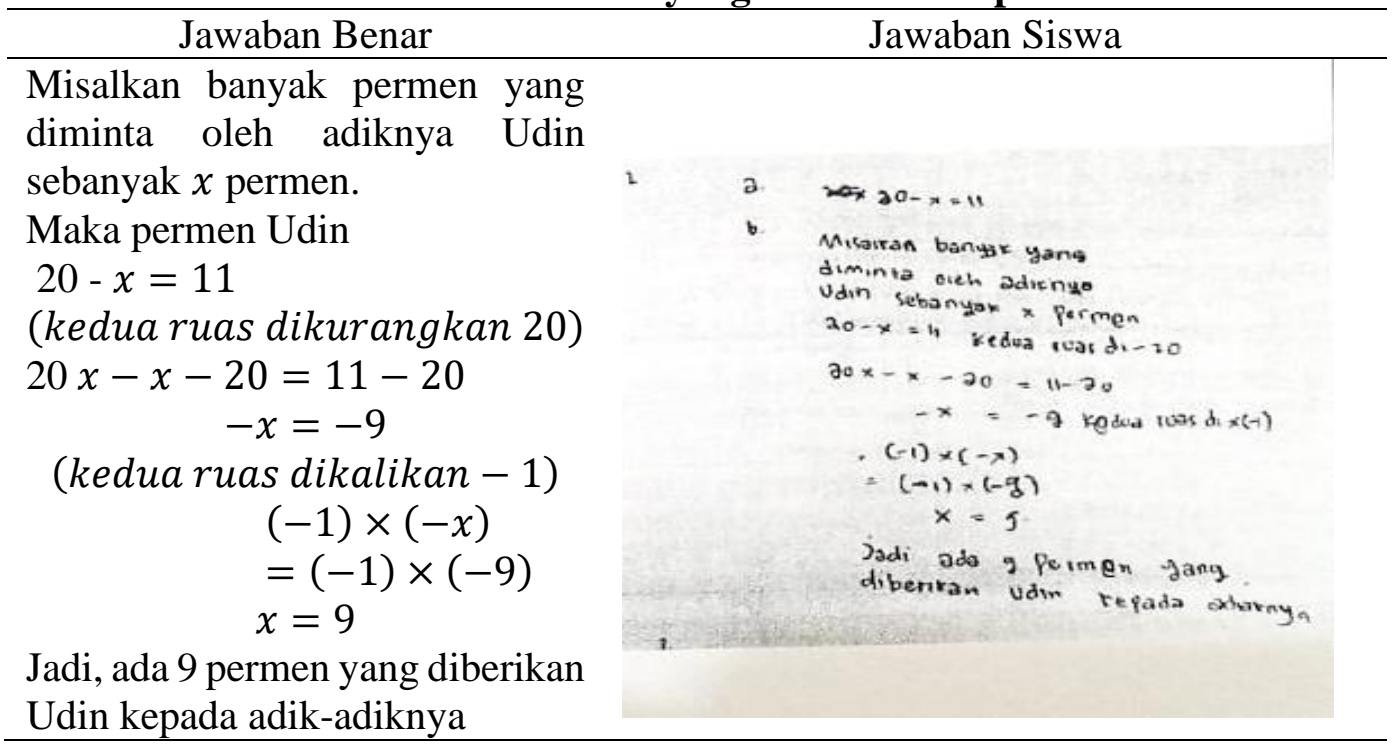

Sumber: diolah dari data penelitian

Hasil penelitian menunjukkan bahwa terdapat peningkatan hasil belajar PLSV melalui Pembelajaran Guided Discovery Learning. Hal ini dapat diketahui dari hasil tes Peningkatan Hasil Belajar PLSV melalui Pembelajaran Guided Discovery Learning. Hasil tes diperoleh nilai rata-rata 78,4 , nilai tersebut lebih dari kriteria ketuntasan minimal (KKM) yang ditetapkan oleh sekolah yaitu 75. Sehingga dapat disimpulkan bahwa peningkatan hasil belajar PLSV melalui Pembelajaran Guided Discovery Learning mengalami peningkatan.

Dengan demikian pembelajaran dengan menggunakan pembelajaran Guided Discovery Learning telah ditunjukkan secara statistik bahwa $t_{\text {hitung }}=12,93>\mathrm{t}_{\text {tabel }}=1,701$, sehingga dapat disimpulkan bahwa peningkatan hasil belajar persamaan linier satu variabel melalui pembelajaran Guided Discovery Learning sudah mencapai ketuntasan.

\section{SIMPULAN}

Pembelajaran dengan Guided Discovery Learning merupakan model yang tepat dalam pembelajaran matematika untuk meningkatkan hasil belajar siswa, seperti memahami dan memecahkan masalah, menghasilkan banyak gagasan, dan mengemukakan bermacam-macam pemecahan, khusunya pada materi PLSV. Siswa dituntut dan dibekali dengan kemampuan menemukan solusi dan dibawah bimbingan guru sebagai fasilitastor. Pembelajaran Guided Discovery Learning bisa diterapkan tingkat Sekolah Dasar (SD), Sekolah Menengah Pertama (SMP) dan Sekolah Menengah Atas (SMA), materi lain yang bisa diterapkan dengan Pembelajaran Guided Discovery Learning diantaranya seperti Operasi Aljabar, Himpunan, Segi Empat, Persamaan Linear Satu Variabel, Bangun Datar, Relasi dan fungsi, Persamaan dan tidak persamaan Linear. Bagi siswa lebih banyak berlatih dan meningkatkan hasil belajar dalam memecahkan soal. Pembelajaran dengan Guided Discovery Learning dapat membantu mengembangkan pengetahuan dalam memecahkan masalah sehingga dapat menemukan pemecahan masalahnya. Jika ditinjau dari nilai rata-ratanya, maka dapat disimpulkan bahwa rata-rata peningkatan skor dari tes awal dan tes akhir terdapat peningkatan (katagori sedang) dari 53,20 menjadi 78,4. Berdasarkan hasil penelitian yang diperoleh terhadap peningkatan hasil belajar dengan Guided Discovery Learning dapat dijadikan sebagai salah satu alternatif model pembelajaran oleh para pendidik. 


\section{UCAPAN TERIMA KASIH}

Terima kasih kami ucapkan kepada para pihak yang telah terlibat dalam hal pengumpulan data dan kegiatan penelitian yang telah dilakukan. Ucapan terimakasih kami ucapkan kepada pimpinan sekolah yang telah memberikan kesempatan kepada penulis dalam rangka kegiatan penelitian serta pengumpulan data.

\section{DAFTAR RUJUKAN}

Amir-Mofidi, S., Amiripour, P., \& H. Bijan-Zadeh, M. (2012). Instruction of Mathematical Concepts through Analogical Reasoning Skills. Indian Journal of Science and Technology 5(6): 1-7. Retrieved from: https://indjst.org/articles/instruction-of-mathematical-concepts-throughanalogical-reasoning-skills

Arikunto, S. (2005). Dasar-Dasar Evaluasi Pendidikan. Revisi. Jakarta: Bumi Aksara.

Culbertson, R., Archambault, J., Burch, T., Crofton, M., \& McClure, A. (2008, August 1). The Effects of Developing Kinematics Concepts Graphically Prior to Introducing Algebraic Problem Solving Techniques (Masters, Arizona State University, 2008). Retrieved June 23, 2021, from http://modeling.asu.edu/modeling/Kinematics-graphical08brief.pdf

Eggen, P \& Kauchak, D. (2012). Strategi dan Model Pembelajaran: Mengajarkan Konten dan Keterampilan Berpikir. Jakarta: Indeks.

Ferawati, F., \& Suhendri, H. (2020). Efektivitas Model Discovery Learning dan Problem Based Learning terhadap Berpikir Kreatif dan Kemampuan Pemecahan Masalah Matematika. JKPM $\begin{array}{lllll}\text { (Jurnal Kajian } & \text { Pendidikan }\end{array}$ http://dx.doi.org/10.30998/jkpm.v6i1.8311

Hake, R. R. (1998). Interactive-engagement versus traditional methods: A six-thousand-student survey of mechanics test data for introductory physics courses. American Journal of Physics, 66(1), 64-74. https://doi.org/10.1119/1.18809

Indiastuti, F. (2016). Pengembangan Perangkat Model Discovery Learning Berpendekatan Saintifik untuk Meningkatkan Berpikir Kreatif dan Rasa Ingin Tahu. Jurnal Pendidikan Matematika RAFA 2(1): 41-55. Retrieved from http://jurnal.radenfatah.ac.id/index.php/jpmrafa/article/view/1240

Marantika, A., Handayani, T., \& Putri, A. (2015). Pengaruh Metode Discovery Learning Terhadap Kemampuan Pemecahan Masalah Matematika Siswa Pada Pembelajaran Matematika di SMP Pelita Palembang." Jurnal Pendidikan Matematika RAFA, 1(2):161-83. Retrieved from http://jurnal.radenfatah.ac.id/index.php/jpmrafa/article/view/1229

Nurhayati., \& Marliani, N. (2019). Implementasi Model Pembelajaran Kooperatif Tipe Course Review Horay (CRH) Terhadap Kemampuan Pemecahan Masalah Matematika. JKPM (Jurnal Kajian Pendidikan Matematika), 5(1): 29-36.

Saleh, M., Muhammad I., Murni, Darhim, \& Bansu I.A. (2019). Student s ' Error Types And Reasoning Ability Achievement Using The Indonesian Realistic Mathematics Education Approach. International Journal of Scientific \& Technology Research 8(07): 364-69. Retrieved from: http://www.ijstr.org/paper-references.php?ref=IJSTR-0719-20695

Saleh, M., Ernisa, Aklimawati, \& Mahmuzah, R. (2019). Pembelajaran Inquiri Based Learning Pada Materi Limas SMP Negeri 16 Banda Aceh. Histogram: Jurnal Pendidikan Matematika, 3(2): 199-209. http://dx.doi.org/10.31100/histogram.v3i2.405

Saleh, M., Prahmana, R.C.I., Isa, M., \& Murni. (2018). Improving the Reasoning Ability of Elementary School Student through the Indonesian Realistic Mathematics Education. Journal on Mathematics Education 9(1): 41-53. https://doi.org/10.22342/jme.9.1.5049.41-54

Sugiyono. (2013). Statistika Untuk Penelitian. Bandung: Alfabeta. 
Sugiyono. (2014). Metode Penelitian Kombinasi (Mixed Methods). Bandung: Alfabeta. Widodo, A. (2010). Pendidikan IPA di Sekolah Dasar. Bandung: UPI Press. 
266 Saleh, Satifa, \& Ainun

JKPM (Jurnal Kajian Pendidikan Matematika) Vol.6, No.2 (2021) 